\title{
Telementoring and Telerobotics in Urological Surgery
}

\author{
Yasmin Abu-Ghanem ${ }^{1}$, Sarah Wheatstone ${ }^{2}$ and Benjamin Challacombe ${ }^{1}$ \\ ${ }^{1}$ Guy's and St Thomas NHS Foundation Trust, London, \\ ${ }^{2}$ South London Healthcare NHS Trust, London,
}

UK

\section{Introduction}

For decades, doctors have been able to communicate and deliver medical information over long distances and assist their colleagues in remote locations via teleconsultation using a variety of communication modalities.

These long distance forums are better known today as 'Telemedicine'.

At the simplest level, telemedicine is broadly defined as the transfer of electronic medical data (i.e. high resolution images, sounds, live video and patient records) from one location to another [S. K. Dey Biswas, 2002].

By the use of various technologies as the telephone, computers and the internet, communication between physicians in different locations is being held in real-time, and medical information is broadcasted.

Over the past few decades, this transatlantic communication has become more and more common within the medical field, as telemdecine being utilized by a range of specialties and disciplines, especially dermatology [Burg G ,2005].

Despite the rather simple definition, there is no common concurrence on what telemedicine really is; trying to clarify things, the European Commission describe telemedicine as the "rapid access to shared and remote medical expertise by means of telecommunications and information technologies, no matter where the patient or relevant information is", while the American Medical Association (AMA) has defined telemedicine as "medical practice across distance via telecommunications and interactive video technology" [AMA Joint Report, 1994].

Nevertheless, Telemedicine is not a specific procedure or a system; it is a route to convey medical services by merging between the old and the new, the known, conventional medical care with the benefits of current technology, in order to deliver health care globally [Wootton R, 2001].

This technology offers the opportunity to advise local and distanced physicians during patient session and surgeries and by that may proffer better care for the patients.

Moreover, it is also used to connect medically deprived or geographically distant districts, so that less trained on-site physicians can provide health services using this long-distance help. 
Less developed countries very often suffer from medical deprivation, starting from the distance to the healthcare centres, to the lack of skilled doctors;

Telemedicine opened the way to healthcare techniques, approaches and medical skills that were not even considered in these districts [WHO 2004, WITSA 2006].

\section{Then and now}

Doctors have been able to convey medical information across great distances, even before the initial development of telegraphy by Sir Charles Wheatstone in 1837 or the telephone by Alexander Graham Bell in 1875.

In its early manifestation, described in the early 1900, people living in remote areas of Australia used two-way radios, powered by a dynamo driven by a set of bicycle pedals, to communicate with the Royal 'Flying Doctor Service of Australia'.

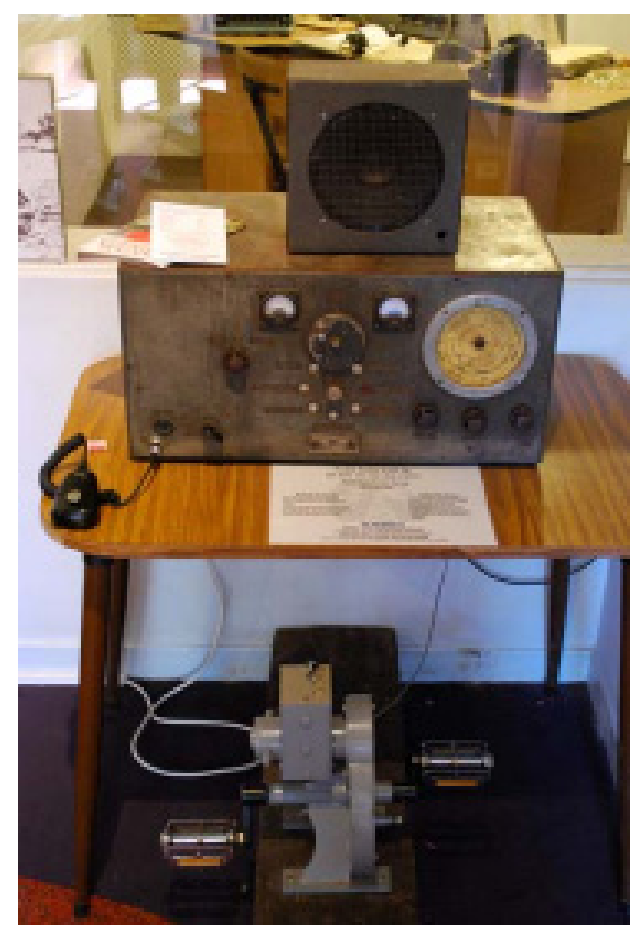

Fig. 1. Traeger pedal-driven radio

The original 1927 Traeger pedal-driven radio receiver at the Royal Flying Doctor Service Station in Alice Springs, Northern Territory, Australia (Challacombe B. et al, 2010).

Other Telemedicine examples date back to the 1930s, when widespread radio communication has just been established. Then it was used to link physicians worldwide and transfer medical information. 


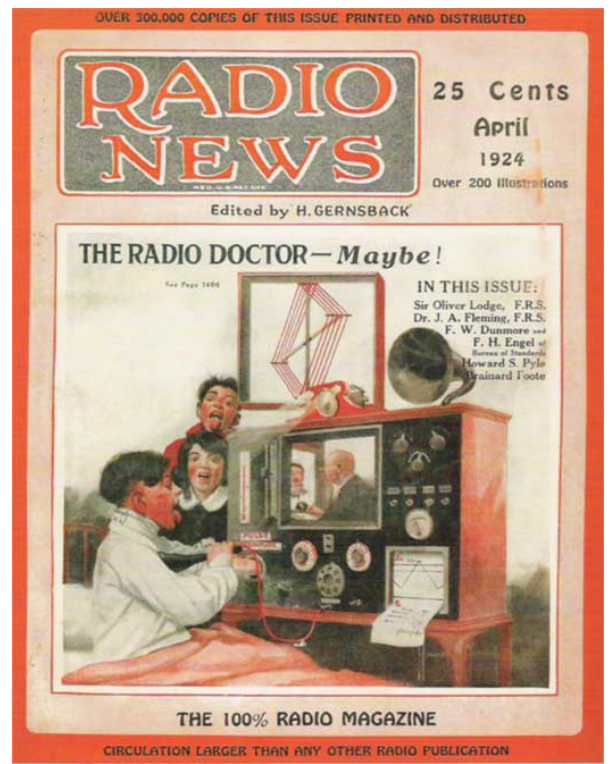

Fig. 2. "The Radio Doctor-Maybe!" Radio News, April 1924

Radio News magazine cover (science magazine of the mid-1920s) predicts the potential progress in telecommunication (radio, telegraph, telephone and television) in medicine ('Radio News', April 1924)

The real development of the telemedicine started by early 1960's, as the National Aeronautics and Space Administration (NASA) used it to deliver physiological parameters from both the spacecraft and the space suits during missions [Bashshur and Lovett, 1977]. Doing so, NASA allowed the following development of satellites communications and telemedicine.

By late 1970's, satellite telemedicine was founded, and paramedics in distant Alaskan and Canadian villages were linked with hospitals in out of reach towns or cities via ATS-6 satellites.

Since the medical world was able to see the benefits of rapid and precise communication over large distances and its potential to aid patients, the concept of 'healing at a distance' has been explored and developed vastly.

Over the last years, it has become part of a growing number of medical specialties such as oncology, pathology, radiology, cardiology, surgery, psychiatry, emergency medicine, nephrology and urology.

\section{Telemedicine, looking through the keyhole}

Over the last two decades, there has been an ever-increasing number of minimally invasive surgical techniques, also known as the "keyhole procedures"; including laparoscopic and robotically assisted surgery. 
This is a modern surgical technique in which operations are performed through small incisions (about $0.5-1.5 \mathrm{~cm}$ ) as compared to the larger incisions needed in laparotomy.

In order to view the operative field, the laparoscopic surgery uses a video camera that displays the images on TV monitors for enlargement of the surgical elements.

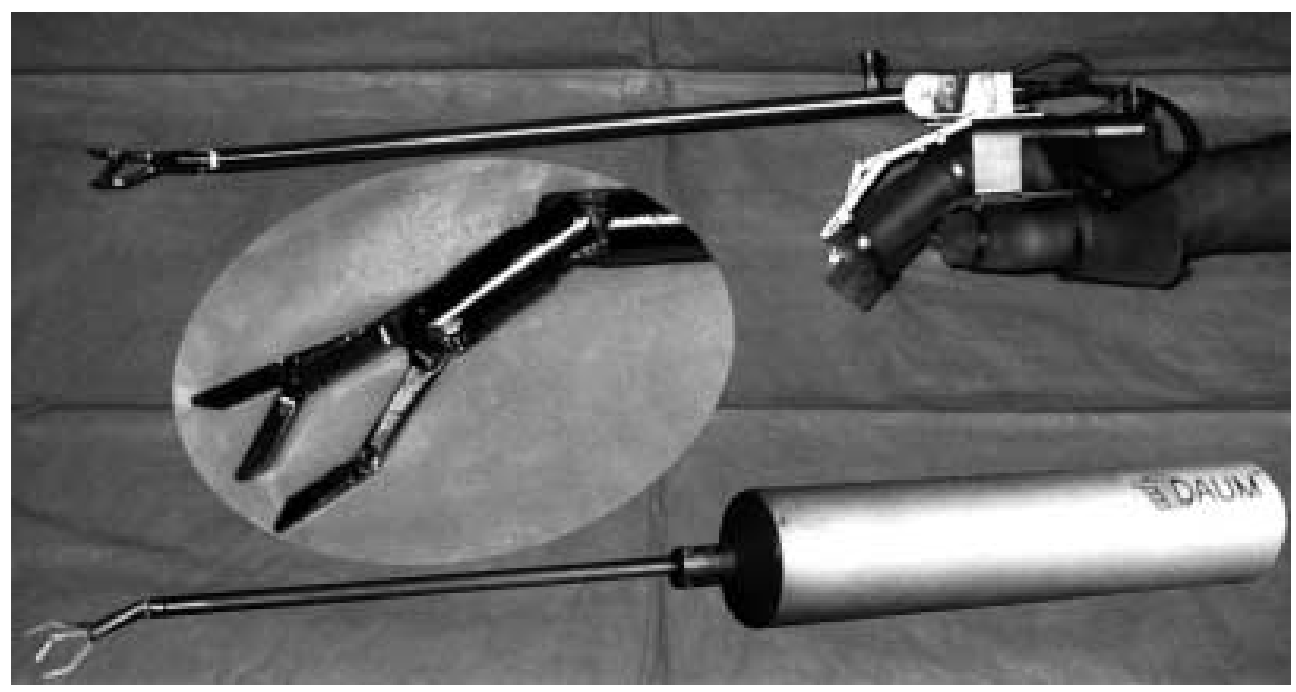

Fig. 3. Laparoscopic instruments, The DAUM EndoHands: Local and remote (Stoianovici D. et al, 2000).

Although these procedures were in evolution for several decades, it was not until the mid1990's that they became acceptable surgical techniques in urology and general surgery. Prior to that, the only specialty performing laparoscopy on a widespread basis was gynecology, mostly for moderately short, simple procedures.

Today, after been proven to produce clinical benefits for countless patients, laparoscopic procedures have advanced to becoming a leading technique in our daily practice.

Minimally invasive surgeries, when performed by experienced surgeons, are favorable for the patients themselves, the hospital and the operating surgeons, with regard to length of hospital stay, return to full activity, and improved cosmetic results [Challacombe B, 2010]. ; Also, they are often more cost-effective than open procedures.

Furthermore, since such surgical procedures are viewed by means of a television monitor they are considered to be ideally suited for the transmission of video images to other sites, and thus, creating a field in which telemedicine techniques can be easily incorporated.

However, although laparoscopic surgery is undoubtedly profitable in terms of patient outcomes, the procedure is more difficult from the surgeon's perception when compared to conventional, open surgery. These procedures are technically demanding, difficult to master and have associated complications that are inversely related to surgeon experience, therefore, having a significant learning curve. 


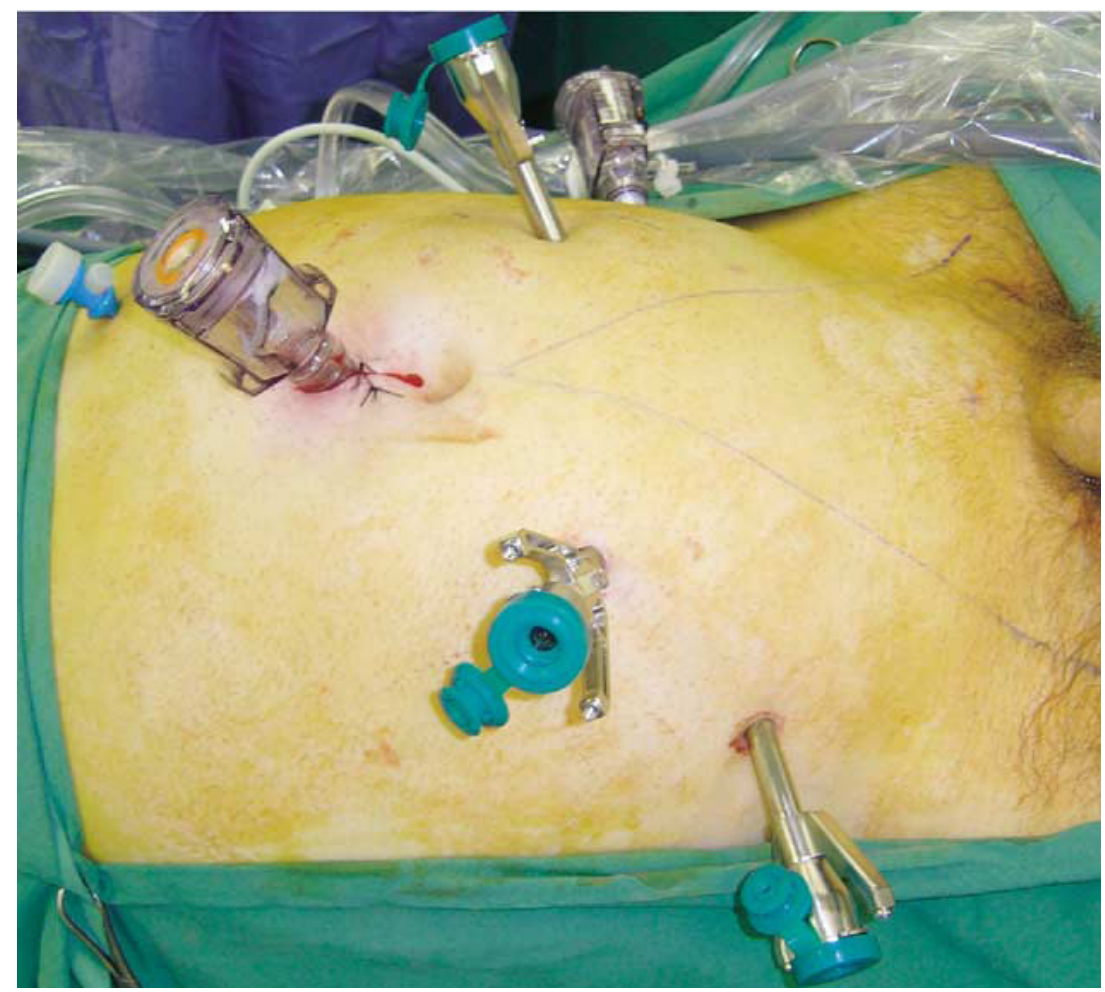

Fig. 4. Minimal Access Surgery Positioning of six ports in a keyhole operation (Van Appledorn S. et al, 2006).

The initial high complication rates associated with minimally invasive surgery and a lack of experienced endoscopic surgeons have raised concerns relating to training and, most importantly, patient safety, consequently, generating a doubt regarding the role of minimally invasive procedures in everyday clinical practice.

However, since the key factor is better training and guidance, it seems that telemedicine may just be the answer to these concerns

By using a real-time video and information transfer, mentoring via telemedicine offers the potential to improve surgeons' skills worldwide and to increase the availability of minimally invasive surgery through video-assisted surgery and through remote instruction.

This long distance guidance, also known as telementoring, may actually answer some of these concerns by allowing better training by closer and tighter guidance.

\section{Telementoring}

Telesurgical education and mentoring has evolved as an important subset of telemedicine. When applied to surgery, telementoring is used when an experienced surgeon assists or directs another less experienced surgeon who is operating at a distance. 
By the usage of two- and three-dimensional, video-based laparoscopic procedures as a platform for real-time transmission, one health care professional can guide, direct, and interact with another, in a different location during an operation or clinical episode.

Communication abilities keep advancing along with technology. These facilities vary from a simple verbal guidance while watching a real-time operation transmitted by video, to indicating target areas on the local monitor screen (telestration), controlling the operative camera, or taking over as the assistant by controlling instruments via a robotic arm.

\subsection{Technical considerations}

The key point in telemedicine, is offering the ability to bring the encounter to any desk-top, of any provider, at any time, anywhere in the world, at a good picture and audio quality.

A high-speed connection with sufficient bandwidth (the total amount of data sent on the network per second. It usually refers to the maximum application throughput) is required for a proper, high quality telementoring system.

For example, an integrated services digital network (ISDN) connection, with a bandwidth of $384 \mathrm{kB}$ per second (six lines) is required to give sufficient picture quality for precise elucidation by the adviser (although clinical work has been carried out using bandwidths as low as $128 \mathrm{~Kb}$ per second [Rosser JC, ,1999].

In terms of connection improvement, the broadband Internet services, as the asymmetric digital subscriber line (ADSL), cable modem service and direct satellite links, have greatly enhanced the telemedicine links, and minimized the delay between the two distant physicians.

A connection delay of less than $250 \mathrm{~ms}$ is most likely to be ideal for increased precision, although greater time delays have been shown to be tolerable. Although delays over $500 \mathrm{~ms}$ (half a second) are quite noticeable [Fabrizio MD, 2000], surgeons are generally able to compensate for delays of up to $700 \mathrm{~ms}$ for remotely performing a surgical task (telesurgery), such as suturing with a robotic device.

Security is one of the main issues to be addressed in terms of clinical data being delivered. In order to ensure it, a VPN ('virtual private network'), is used, a network path or connection that does not allow other connections to or from it.

For the past several years, the potential of telementoring has been illustrated in inaccessible environments. For example, the Johns Hopkins' Urology team who telementored a laparoscopic nephrectomy to Italy, or adrenalectomy, varicocelectomy, renal cyst ablation and radical nephrectomy to countries like Austria, Singapore and Germany [Fabrizio MD,1998; Rodrigues N, 2003].

These early studies have shown that telementoring can significantly shorten the learning curve and decrease the total complication associated with endoscopic surgeons' lack of experience [Challacombe B, 2005].

\subsection{Telemedicine in the Robotics era}

The next significant advance in the field of surgery and especially in urology was robotic surgical technology, primary used for procedures like radical prostatectomy for localized prostate cancer. 
After it has initially been developed by the US department of defence for use in military battlefield applications, robotic technology was taken on for use in human surgical applications.
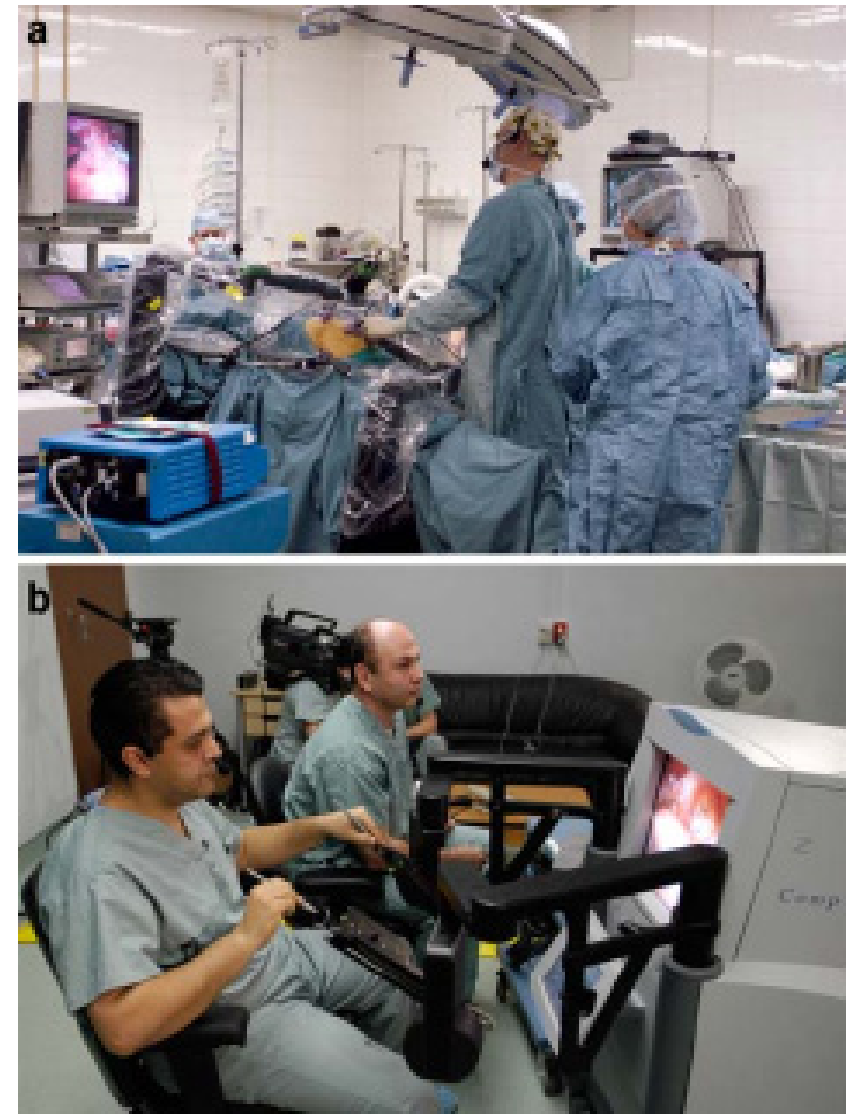

a. Dr. Mehran Anvari at the Zeus TS robotic platform.

b. The remote patient. (Courtesy of M. Anvari,MB, BS, PhD (Challacombe B. et al, 2010).

Fig. 5. Zeus TS robotic platform

Hence, recognizing the potential, around late 90's, two companies introduced their surgical systems almost simultaneously; the Computer Motion, Inc, introduced the Zeus Surgical System and the Intuitive Surgical, Inc, developed its da Vinci Surgical System.

And almost by night, the idea of real telesurgery took one step further, to a real, practical concept.

One of the first examples is the a laparoscopic cholecystectomy, successfully carried out in 2001, using the Zeus robot with the surgeon in New York and the patient in Strasbourg, France [Marescaux J, 2001]. A procedure known today as the 'Lindbergh procedure', named after Charles Lindbergh's first trans-Atlantic flight from New York to Paris. 
And by 2005, the da Vinci surgical system had its first public appearance, when Colonel Noah Schenkman of the Walter Reed Army Medical Center performed live nephrectomy on two pigs at the American Telemedicine Association (Washington, DC) [Hanley EJ, 2005].

That operation made history by also being the first to use stereoscopic surgical video streaming, and the first telesurgery over the Internet.

Meanwhile, the Zeus Surgical System was phased out after company takeover, leaving the da Vinci system to thrive around the world, becoming the the current state of the art computer assisted robotic tool today, not only in the field of urology but also in cardiac, gastrointestinal, gynaecologic, paediatric and ENT surgery [Dasgupta P, 2008].

Robotic surgery represents the latest method known for overcoming the obstacles of standard laparoscopy. It trounces various technical challenges by allowing enhanced 3-D visualization, improving dexterity, surgical precision and access, as well as increased range of motion [Ali MR, 2008; Dasgupta P, 2008; Wexner S, 2009].

However, while the potential from robotic procedures seems patently obvious, the learning curve is undeniably steep, therefore requiring lot of guidance and training, making these procedures ideal suited for telementoring.

The robotic surgical system allows the surgeon to transmit data and images to his mentor on line, at any given stage of the operation. The mentor can direct and observe the surgeon is his following steps and indicate appropriate tissue planes or specific lines of incision during the procedure [Challacombe BJ, 2006].

Moreover, in the modern da Vinci Si HD, the system has dual controls, enabling the surgeon to operate while receiving constant feedback from the mentor, who can take over at any point of the operation. That allows the trainee early independence and enhanced training.

Following successful experiments with localized robotic surgeries, the concept was perceived to be extended to remote surgery.

Having its ultimate assemblage for telemedicine, the da Vinci system is often referred to as a "telerobotic" system. In a non robotic operation (open or laparoscopic) the mentor may be remote from the patient, and still advice the leading surgeon, via telecommunicating. However, in order to interfere and control the minimally invasive manipulation, he has to be not only adjacent to the patient, but also scrubbed at all time.

On the other hand, during a robotic procedure, although the mentor will usually be near the patient in the same room, some facilities now have it in a nonscrub area which increases accessibility for the primary surgeon that can now approach easily at any point of the operation and assist, intervene, and carry out a range of operations.

Moreover, a mentor can be present on the patient side as an assistant, and the surgeons are able to switch primary surgeon responsibilities back and forth depending on need. Recently, the da Vinci system has been modified and enabled for use over the Internet as well.

In most general terms, in a telerobotic procedure, the physician is seated at a surgeon console at a distant site, and manipulates remote controls. The joystick or remote control movements are converted into digital signals which travel via the telecommunication network to the robotic system on the patient side. These signals are received by the surgical 
column and translated from their digital form into movements of the robotic surgical arms within the surgical field (ie, inserted into the patient). The surgeon oversees these movements.

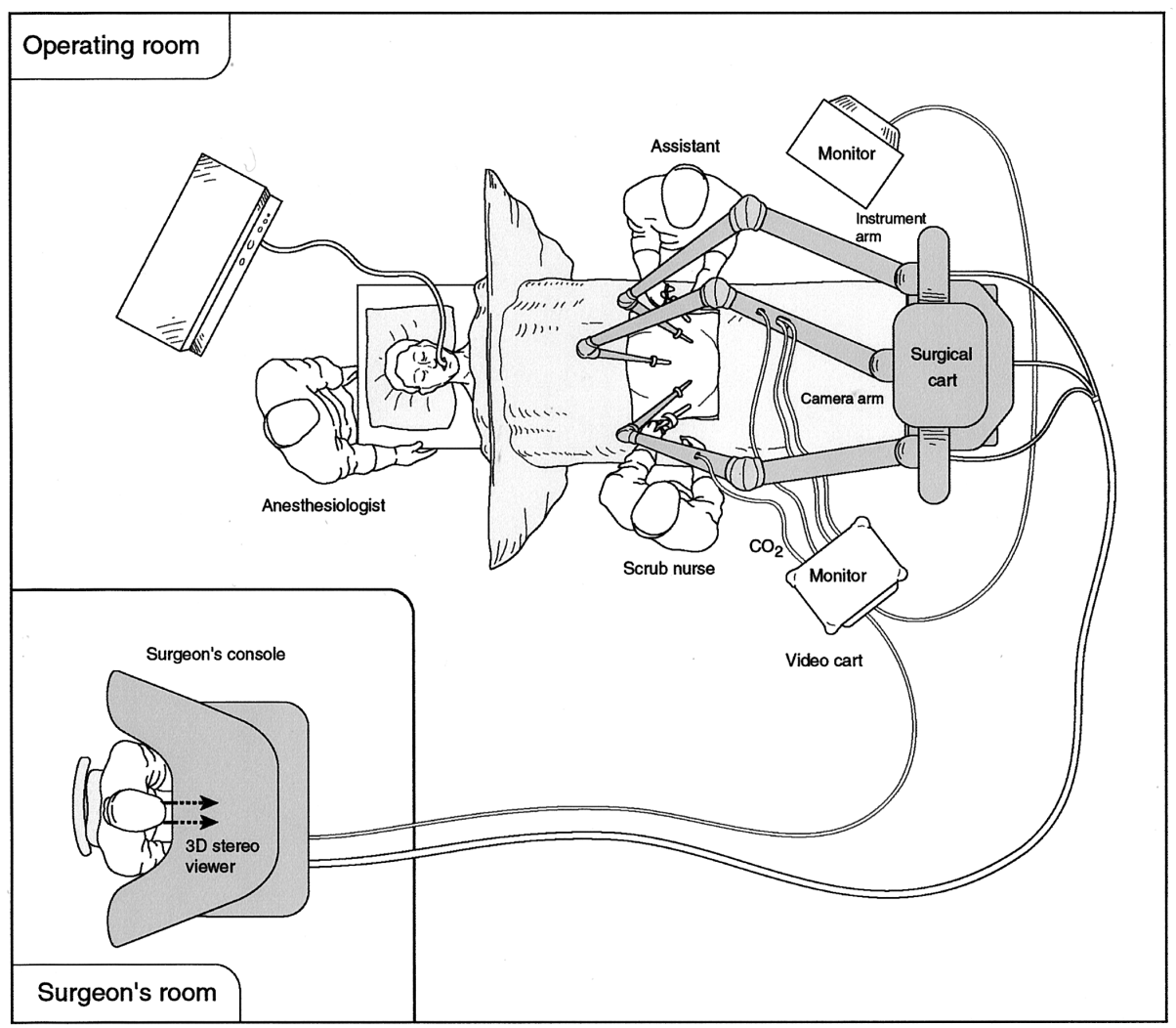

Fig. 6. da Vinci system in operating room (Abbou CC. et al, 2001).

\subsection{Telesurgical Telementoring}

Since it was first introduced in the early 2000's, the robotic techniques have widely adopted, since it has been shown that they have the advantages of reduced blood loss, reduced pain, shorter inpatient stay and convalescence when compared to open approaches. High volume centres performing these techniques report excellent results with regard to oncological and functional outcomes but there is a lack of level 1 evidence to support their use.

It is likely that robotic prostatectomy using the da Vinci surgical system will be the most common technique in the UK within the next few years and over \&)\% of radical prostatectomies are performed this way in the United States.

The rapid evolutions of robotics and surgical simulation techniques have facilitated the possibilities of telesurgery with telementoring, telepresence, and telerobotics [Ballantyne $\mathrm{GH}, 2002]$. 
Therefore, after their initial success with telementoring, the Johns Hopkins Urobotics group established the 'telesurgical mentoring'.

This system increased the telementoring distance to 3.5 miles by integrating the real-time video display, audio and telestration over live video with control of a robotic arm that manipulated the laparoscope, and access to electrocautery for tissue cutting or hemostasis during the telementored cases [Schulam PG, 1997].

This setup was further used in the next following years, in various procedures over great distances, like laparoscopic adrenalectomy between Baltimore, MD and Innsbruck, Austria, or laparoscopic varicocelectomy between Baltimore and Singapore [Lee BR, 1998].

Many doubts have been raised regarding the accuracy and efficiency of the robotic system, and the benefits of telesurgery were outweighed by the costs and complexity of the robotic procedure.

Therefore, in 2002, the Hopkins (Baltimore, MD) and Guy's Hospital (London, England), collaborated to form the first randomized controlled trial of telerobotic surgery [Challacombe BJ, 2003].

In this study, the groups compared percutaneous needle insertion performed by a transatlantic telerobotic arm, to urological surgeons. Though the robot was slower than the human it was more accurate both locally and remotely, compared with human operators, as it made less attempts for successful needle insertions [Challacombe BJ, 2005].

Moreover, the patients in the telerobotic arm group have shown no conversions, no significant complications, and outcomes have been similar to standard laparoscopic surgery.

Since telemedicine relays entirely on the quality of the signal, and the time delays, the technical aspects of transmission have become one of the biggest concerns regarding the telerobotic medicine.

The issue of reliability of the link itself, as it could be potentially disastrous to lose a connection at a critical operative stage, has been a major obstacle in the expectance of telemedicine as part of our medical practice.

In order to assess the influence of the technical factor, Challacombe et al. demonstrated that there were no lost signals during the entire procedure. Furthermore, when this group and others investigated the effect of differing time delays on surgical performance, they supported the previous work of Fabrizio et al. who found that errors and task completion times increase only with delays above $500 \mathrm{~ms}$ [Anvari N, 2005].

Thus, making it safe to conclude that telerobotic assistance was a significant enabling tool for this type of surgery [Sebajang H, 2006].

\section{The future}

In the last few decades, medicine has developed alongside a staggering race for technology. Technological Innovations are being vastly used by different medical disciplines, creating the phenomenon we described as telemedicine [Satava RM, 2005]. 
As technology is being incorporated in the operating room, the complexity of the available surgical equipment continues to advance unabatedly. However, the cost of hardware, software, and the telecommunication link itself begins to fall, and by that, making telesergery and telementoring more accessible, with hopes of becoming a routine application.

Much has been said about the advantages within telemedicine; by telemedicine and telementoring, surgeons can facilitate procedures that would otherwise not even been attempted due to complexity, difficulty, and lack of local surgeon experience.

Using telementoring, surgeons are being guided by their mentors, allowing early independence and reducing learning curves as well as learning time, in new and complex procedures.

Mentors can be "on call" and available at any point, when unexpected operative findings are discovered and aid in any urgent situations owing to their previous experiences.

Surgeons with various expertise can assist and advice their colleges from around the world on their learning, thus, making technically advanced operations available worldwide; developed or underdeveloped countries with remote populations can benefit greatly from telesurgical operating, as a robotic system can be installed locally and an onsite team can be taught how to set up and dock the system [Wynsberghe A, 2008].

In view of the fact that the technology has been available for several years, added to the advantages mentioned above, one would expect that the field of international telementoring will vastly and quickly expend. However, not only that it hardly expanded, for now, it failed to become a bigger part of our medical practice.

Probably the main question asked today, is why; while acknowledging the remarkable benefits technological developments have provided, it is also of great importance to acknowledge their potential harm.

First, is the ethical considerations; one of the ethical dilemmas involves protecting patient confidentiality and privacy while expanding access to information. An electronic communication that includes delivery of sensitive medical data may cause the principles of autonomy and confidentiality to be inadvertently violated [Yeo CJ, 2003].

Although using the VPN, access computerised medical information recorded via the telecommunications network can potentially be compromised and subsequent interruption as honest mistakes, or even deliberate hacking may accrue during telesurgical procedures, which could result in highly sensitive and confidential medical information being shared by basically anyone who could access it.

Another ethical dilemma is the dehumanizing of the patient or reducing it to an object [Wynsberghe A, 2008]. The unconventional long-distance or online consultations practised in telemedicine render it difficult to define the patient-physician relationship.

Many believe that minimizing distances and overseas consultations may actually jeopardise the physician patient relationship. In many of the international cases, a physician may find him self treating a patient he never examined or communicated with, or even met before.

It is clear that every physician has an ethical obligation to his patient; however, it is impossible to determine whether the physician has treated the patient to the best of his 
capability, and thus decide whether values as integrity and competence, have been strictly held.

Nevertheless, the question whether a patient has to be examined by a certain physician in order to be treated by him should not be related merely to telemedicine; many physician give consultation via the phone or different medical website, without having any knowledge about the patient, apart from what it chose to present.

Another issue that should be addresses, is the differences in both software and hardware capabilities between individual countries.

The cost of buying and installing a high-quality telecommunication system stands, to this date, at approximately $\$ 20,000$. In hard-wired systems (ie, ISDN) it would be logical for the local center to pay for the telesurgical link, but this may financially prohibit exactly the smaller remote medical centers that stand to benefit most from such systems.

Thirdly, while operating via international telerobotic surgery, a European surgeon may mentor and guide another physician from everywhere around the world. However, to this date, medical qualifications from the European Union are not recognized from the United States and vice versa, therefore, advising to a college overseas who even has his own country specific medical cover may actually raise some ethical and legal issues.

Hence, special arrangements would need to be in place for patient responsibility, and the remote surgeon would have to take liability for the perioperative welfare of patients.

In conclusion, the increasing reliance on computers and information technology in has opened a new window of opportunities to access to medical knowledge and expertise worldwide, simultaneously to cutting costs and increasing efficiency.

From its early examples in early 1900, to the telerobotic era, telemedicine has proven to be efficient in improving availability of selected basic, intermediate and advanced medical facilities, improving diagnoses of diseases due to availability of specialist opinions, convalescing learning curves of advanced and complicated procedures, increased utilization of specialists and in assisting physicians and patients world wide and even reduction the urban migration from villages to major cities due to better medicare.

Therefore, thought ethical, technical and financial issues should be addressed throatily, it is very difficult to comprehend why telecounselling and mentioning has not yet become a major part of our clinical and practical everyday life.

There is no obvious reason why a surgeon should experience difficulties during their learning and hold-up their chance of independence, instead of just taking the opportunity to be instructed by an experienced colleague wherever they are located.

In the future, telemedicine may remedy the uneven geographic distribution of healthcare resources [Challacome BJ, 2006]. It can also address the significant discrepancies in the quality of care available to members of different economic classes [Schulam PG, 1997].

\section{References}

[1] Abbou CC, Hoznek A, Salomon L, Olsson LE, Lobontiu A, Saint F, Cicco A, Antiphon P, Chopin D (2001). Laparoscopic radical prostatectomy with a remote controlled robot. J Urol. 2001 Jun;165(6 Pt 1):1964-6. 
[2] Ali MR, Loggins JP, Fuller WD, Miller BE, Hasser CJ, Yellowlees P, Vidovszky TJ, Rasmussen JJ, Pierce J. (2008). 3-D telestration: a teaching tool for robotic surgery. J Laparoendosc Adv Surg Tech A. 2008 Feb;18(1):107-12.

[3] Annual Meeting of the American Medical Association (AMA) 1994 ;available <http://www.ama-assn.org/ama/pub/about-ama/our-people/amacouncils/council-science-public-health/reports/19941998-reports.page>

[4] Anvari M, McKinley C, Stein H. (2005). Establishment of the world's first telerobotic remote surgical service for provision of advanced laparoscopic surgery in a rural community. Ann Surg. 2005, 241:460-464.

[5] Ballantyne GH. (2002). Robotic surgery, telerobotic surgery, telepresence, and telementoring. Review of early clinical results. Surg Endosc. 2002 Oct;16(10):1389402. Epub 2002 Jul 29.

[6] Bashshur R, Lovett J. (1977). Assessment of telemedicine: results of the initial experience. Aviat Space Environ Med. 1977 Jan;48(1):65-70.

[7] Burg G, Hasse U and Cipolat C. (2005). Teledermatology: Just cool or a real tool? Dermatology, 2005;210(2):169-73.

[8] Challacombe BJ. (2003). Trans-oceanic telerobotic surgery. BJU Int 92: 678-680

[9] Challacombe B, Kandaswamy R, Dasgupta P, Mamode N (2005). Telementoring facilitates independent hand-assisted laparoscopic living donor nephrectomy. Transplant Proc. 2005, 37:613-616.

[10] Challacombe B, Patriciu A, Glass J (2005). A randomized controlled trial of human versus robotic and telerobotic access to the kidney as the first step in percutaneous nephrolithotomy. Comput Aided Surg. 2005, 10:165-171.

[11] Challacome BJ, Murphy D, Shah N (2006).Trans-atlantic telerobotic watching using the da Vinci Surgical System. J Endourol. 2006, 20:A229.

[12] Challacombe B, Wheatstone S. (2010). Telementoring and telerobotics in urological surgery. Curr Urol Rep. 2010 Feb;11(1):22-8.

[13] Dasgupta P. (2008). Robotics in urology.Int J Med Robot. 2008 Mar;4(1):1-2.

[14] Dey Biswas S. K.; Guest Lecture delivered at BIC Workshop, JBTDRC, Nov. 2002.

[15] Fabrizio MD, Lee BR, Chan DY. (2000). Effect of time delay on surgical performance during telesurgical manipulation. J Endourol. 2000, 14:133-138.

[16] Hanley EJ, Miller BE, Herman BC. (2005). Stereoscopic robotic surgical telementoring: feasibility and future applications. Presented at the 10th Annual American Telemedicine Association. Denver, Colorado; April 17, 2005.

[17] Lee BR. (1998) International surgical telementoring: our initial experience. Stud Health Technol Inform 50: 41-47

[18] Marescaux J, Leroy J, Gagner M (2001). Transatlantic robotassisted telesurgery. Nature. 2001, 413:379-380.

[19] 'Radio News' magazine, April 1924.

[20] Rodrigues Netto N Jr, Mitre AI, Lima SV. (2003). Telementoring between Brazil and the United States: initial experience. J Endourol. 2003 17:217-220.

[21] Rosser JC Jr, Bell RL, Harnett B.(1999). Use of mobile lowbandwidth telemedical techniques for extreme telemedicine applications. J Am Coll Surg. 1999, 189:397-404.

[22] Satava RM. (2004).Future trends in the design and application of surgical robots. Semin Laparosc Surg 2004, 11:129-135. 
[23] Schulam PG, Docimo SG, Saleh W. (1997). Telesurgical mentoring. Initial clinical experience. Surg Endosc 1997, 11:1001-1005.

[24] Sebajang H, Trudeau P, Dougall A. (2006).The role of telementoring and telerobotic assistance in the provision of laparoscopic colorectal surgery in rural areas. Surg Endosc. 2006, 20:1389-1393.

[25] Stoianovici D.(2000). Robotic surgery. World J Urol. 2000 Sep;18(4):289-95.

[26] Van Appledorn S, Bouchier-Hayes D, Agarwal D, Costello AJ. (2006). Robotic laparoscopic radical prostatectomy: setup and procedural techniques after 150 cases. Urology. 2006 Feb;67(2):364-7.

[27] vanWynsberghe A, Gastmans C: Telesurgery. (2008). an ethical appraisal. J Med Ethics 2008, 34:e22.

[28] Wexner SD, Bergamaschi R, Lacy A, Udo J, Brölmann H, Kennedy RH, John H (2009). The current status of robotic pelvic surgery: results of a multinational interdisciplinary consensus conference. Surg Endosc. 2009 Feb;23(2):438-43. Epub 2008 Nov 27.

[29] Wootton R. (2001). Recent advances: Telemedicine. BMJ. 2001 Sep 8;323(7312):557-60.

[30] World Health Organisation (WHO), Department of Essential Health Technologies: 'Taking basic health solutions to countries': Strategy 2004-2007 'eHealth for Healthcare Delivery' <http://www.who.int/eht/en/eHealtwfph_HCD.pdf>.

[31] World Information Technology and Services Alliance (WITSA) (2006) 'Health Care and Information and Communications Technologies: Challenges and Opportunities' <http://www.witsa.org/papers/WITSA-HIT-final.pdf>.

[32] Yeo CJ. (2003). Ethical dilemmas of the practice of medicine in the information technology age. Singapore Med J. 2003 Mar;44(3):141-4.

[33] Van Appledorn S, Bouchier-Hayes D, Agarwal D, Costello AJ. (2006). Robotic laparoscopic radical prostatectomy: setup and procedural techniques after 150 cases. Urology. 2006 Feb;67(2):364-7. 
(C) 2012 The Author(s). Licensee IntechOpen. This is an open access article distributed under the terms of the Creative Commons Attribution 3.0 License, which permits unrestricted use, distribution, and reproduction in any medium, provided the original work is properly cited. 